\title{
The Role of Nociceptive Neurons in the Pathogenesis of Psoriasis
}

\section{Xuan Zhang and Yanling He* \\ Department of Dermatology, Beijing Chao-Yang Hospital, Capital Medical University, Beijing, China}

Psoriasis is a chronic inflammatory skin disease. Emerging evidence shows that neurogenic inflammation, induced by nociceptive neurons and T helper 17 cell (Th17) responses, has a fundamental role in maintaining the changes in the immune system due to psoriasis. Nociceptive neurons, specific primary sensory nerves, have a multi-faceted role in detecting noxious stimuli, maintaining homeostasis, and regulating the immunity responses in the skin. Therefore, it is critical to understand the connections and interplay between the nociceptive neurons and the immune system in psoriasis. Here, we review works on the altered innervation that occurs in psoriasis. We examine how these distinct sensory neurons and their signal transducers participate in regulating inflammation. Numerous clinical studies report the dysfunction of nociceptive neurons in psoriasis. We discuss the mechanism behind the inconsistent activation of nociceptive neurons. Moreover, we review how neuropeptides, involved in regulating Th17 responses and the role of nociceptive neurons, regulate immunity in psoriasis. Understanding how nociceptive neurons regulate immune responses enhances our knowledge of the neuroimmunity involved in the pathogenesis of psoriasis and may form the basis for new approaches to treat it.

Keywords: psoriasis, nociceptive neurons, neurogenic inflammation, Th17, TRPA1 and TRPV1 receptors

\section{INTRODUCTION}

Skin is a highly sensitive organ that is abundantly innervated by primary sensory nerve endings whose cell bodies are located within the dorsal root ganglia (DRG) and the cranial sensory ganglia (1). The skin contains specific sensory neurons, called nociceptive neurons, that respond to a wide range of noxious stimuli. These stimuli include extreme mechanical stimuli, chemical irritants, and harmful temperature stimuli, which are all capable of causing tissue injury (2). Nociceptive neurons transmit action potentials that induce the pain sensation and trigger the withdrawal reflex (3). Nociceptive neurons also release neuropeptides from peripheral nerve terminals that directly modulate local immune responses (4).

Psoriasis is a chronic inflammatory skin disease characterized by hyperproliferation of the basal epidermal cells, which results in erythematosquamous plaques (5). Clinical reports show spontaneous improvement of psoriatic skin lesions after central or peripheral nerve damage (6), indicating that the nervous system may play an essential role in the development of psoriasis. Moreover, several clinical studies have shown that patients with psoriasis, who suffered insomnia, depression, and anxiety, pointed to these stressors as the main causes of exacerbation of their psoriasis (7-9).

Here we will identify the change in innervation that occurs in patients with psoriasis. We will review the ways nociceptive neurons sense the local environment in skin tissue and then 
evaluate the dysfunction of peripheral sensory neurons in psoriasis. We will also discuss how the neuropeptides that are released by neurons contribute to the regulation of Th17 immune responses as well as examine the role of nociceptive neurons in a psoriatic mouse model. A proper understanding of the role that nociceptive neurons play in shaping the course of psoriasis could have profound implications for our knowledge of psoriasis pathogenesis and may improve our ability to treat the condition.

\section{NOCICEPTIVE NEURONS SENSE THE TISSUE MICROENVIRONMENT}

Similar to the immune system, the peripheral nervous system can detect stimuli directly from the local immune microenvironment. These stimulations can induce excessive excitement and even cause action potentials in nociceptive nerve fibers that evoke pain and/or itching and hyperalgesia. These sensations are produced through various receptors and ion channels, such as transient receptor potential (TRP) channels and inflammatory factor receptors, which are located in free nerve fiber endings.

The TRP channel family, the largest group of noxious stimulus detectors, are $\mathrm{Ca}^{2+}$ permeable channels that play a key role in pain sensation (10). In this review, we will focus on and thoroughly investigate two of the TRP channel subfamilies, transient receptor potential cation channel subfamily $\mathrm{V}$, member 1 (TRPV1) and transient receptor potential cation channel subfamily A, member 1 (TRPA1). TRPV1 is a non-selective, ligand-gated, cationic (mainly $\mathrm{Ca}^{2+}$ ) channel responsive to noxious thermal stimuli in the temperature range above $43^{\circ} \mathrm{C}$. In contrast to TRPV1, TRPA1 is a non-selective, ligand-gated, $\mathrm{Ca}^{2+}$ channel that responds to noxious cold stimuli below $17^{\circ} \mathrm{C}$ (11). TRPA1 is almost exclusively found in TRPV1-expressing populations of sensory neurons (12). Numerous studies have found that there is cross-sensitization and cross-desensitization between TRPV1 and TRPA1 channels (13-15). Recently, it has been reported that a membrane adapter protein called Tmem100 might form a heteromeric channel construct, playing a fundamental regulatory role in TRPV1-TRPA1 interaction (16).

TRPV1 and TRPA1 sensitization occurs through a mechanism involving multiple protein kinases, such as protein kinases $\mathrm{C}$ and $\mathrm{A}$ (PKC and PKA, respectively) and $\mathrm{Ca}^{2+} /$ calmodulin dependent kinase II (CAMKII) (17). Elevated PKC, PKA, or CaMKII activity is associated with sensitization and activation in the nociceptive neurons $(18,19)$. Numerous studies have reported that inflammation mediators can induce inconsistent activation of nociceptive neurons through $G$ protein-coupled receptors (GPCRs) or receptor tyrosine kinases (RTKs) via cAMP/PKA, $\mathrm{PLC} / \mathrm{PKC}$, and CaMKII second messenger-signaling pathways $(17,20)$. These include cytokines [tumor necrosis factor (TNF)], interleukins (IL-1b, IL-6, IL-17A), chemokines, neuropeptides [calcitonin gene-related peptide (CGRP), substance P (SP), and Vasoactive intestinal peptide (VIP)] (21-27). These phenomena provide a treatment target for alleviating skin discomfort and regulating the immune response which will be discussed below.

\section{INNERVATION IN PSORIASIS}

The expression of TRP channels (TRPV1, TRPA1) is elevated in psoriatic skin $(28,29)$. TRP channels are also expressed on nonneuronal cells (30) and, at present, clinical studies targeting the change of nociceptive neurons in psoriasis are still unavailable. Therefore, we have settled for a review of the variation of the primary sensory nerve system.

\section{Altered Quantity of Nerve Fibers in Psoriasis}

Numerous studies have shown that, for every measurable aspect, innervation in psoriatic lesions is higher than in non-psoriatic skin, including the total number of nerve fibers (31), density (31-33), total length (34), and the proportion of nerve fiber penetration into the epidermis (35). However, other investigators have reported conflicting results. It has been reported that protein gene product 9.5 (PGP9.5)-positive nerve endings are completely absent in long-established psoriatic lesions (36). The number of PGP9.5 ${ }^{+}$epidermal immunoreactive nerve fibers was also decreased in highly inflamed psoriatic skin areas (37). These differences may be due to variations in the progression of psoriasis and the duration of time the lesion has been present on the skin.

Nerve ending density is regulated by neurotrophins and other factors of nerve reduction. Nerve growth factor (NGF) and the epidermal growth factor, amphiregulin, facilitates the outgrowth of nerve endings $(38,39)$, while semaphorin-3A acts as a negative regulator of nerve fiber growth (40). The altered innervation in psoriatic lesions is due to changes in the balance of expression of nerve growth regulators. Related studies have reported that, in psoriatic lesions, the expression of semaphorin$3 \mathrm{~A}$ is decreased $(31,33,41)$ and the expression of amphiregulin $(35,41), \operatorname{NGF}(33,34,41)$, tropomyosin receptor kinase A (TrkA) $(35,41)$, and P75 neurotrophic factor receptors (p75NTR) (42) are enhanced. It was also confirmed, in a psoriasis-like mouse model, that anti-neurotrophins treatment can reduce innervation in and significantly relieve psoriasis-like lesions, suggesting that neurotrophins participate in the pathogenesis of psoriasis by regulating the growth of nerve fibers (43).

\section{Neuropeptide Content in Psoriasis}

In the skin, neuropeptides are mainly synthesized and secreted by $\mathrm{C}$ fibers, however, a small part of A $\delta$ fibers and autonomic nerve fibers can express neuropeptides $(44,45)$. Neuropeptides can also be released by keratinocytes, microvascular endothelial cells, Merkel cells, fibroblasts, and leukocytes under certain physiological conditions (46). Several immunohistochemical studies have demonstrated a change in the expression of neuropeptides in psoriasis. It has been reported that the number of peptide-containing nerve fibers in psoriatic epidermal tissue is elevated as compared to non-psoriatic nerve tissue. The number of $\mathrm{SP}^{+}$nerve fibers increased by six, and the number of $\mathrm{CGRP}^{+}$ nerve fibers doubled $(33,47)$. Increased NGF is responsible for these elevations (48). It has been confirmed that the content of CGRP and SP in psoriatic lesions in psoriasis is elevated (35), accompanied by an increased expression of their receptors 
$(41,49)$. Moreover, the content of neuropeptides in the plasma of patients with psoriasis is also elevated, which corresponds with the psoriasis area and severity index (PASI) scores $(50,51)$.

However, there are conflicting reports that the quantity of peptidergic nerve fibers are significantly decreased in psoriatic lesions (37). It was recently reported that in imiquimod (IMQ)induced psoriasis-like lesions, there was an increase in the density of non-peptidergic nerve fibers while the density of peptidergic nerve fibers decreased (43). We can speculate that the IMQinduced psoriasis-like mouse model is similar to the advanced stage of psoriasis, while the decrease in peptidergic nerve fibers is caused by neuropeptides release.

\section{Abnormal Nociceptive Neurons Function in Psoriasis}

Nociceptive neurons play a role in generating pain and pruritus sensations. Abnormal function of these neurons can cause unpleasant skin symptoms in patients. It was found that nearly $90 \%$ of patients with psoriasis suffered skin symptoms, including pruritus, discomfort, and hyperalgesia (52). Pruritus is the most common symptom of psoriasis with about 64 to $84 \%$ of patients complaining of itching (28). Nearly half (43.6\%) of patients experience pain in the lesion area, accompanied by a decreased pressure pain threshold, especially in the scalp and palm areas (53). Similarly, they had lower cold pain thresholds (54). Furthermore, patients with psoriasis who regularly experienced a decreased cold sensation threshold but an increased thermal threshold also had an increased sensitivity to temperature change (55). Moreover, there was a tendency for the pressure and pain thresholds to be decreased in the non-lesion areas of patients with psoriasis $(53,54)$. The results of these studies show that, in psoriasis, nociceptive neurons fail to consistently transmit sensory signals in lesion as well as non-lesion areas.

Mild systemic inflammation may contribute to the abnormal nociceptor function that is observed in psoriasis (56). The improved PASI scores as well as an improvement in pain intensity are observed after systemic therapy (57), which indicates that abnormalities in sensory function are related to the course of the condition rather than to organismic malformations of the nervous fibers. It is mentioned above that the increased inflammatory factors observed in psoriasis can induce abnormalities in the sensitivity of nociceptive neurons. Research has confirmed that, compared to healthy controls and non-itchy or non-pain lesions, pruritic psoriatic skin contains elevated gene transcription levels of IL-17, IL-23, and IL-31 (28) and hyperalgesia psoriatic skin has higher expression levels of IL-33 (53). IL-17, IL-31, and IL-33 are all important inflammatory factors in the pathogenesis of psoriasis (58). Animal experiments have confirmed that IL-33 can induce dysfunction in sensory nerves (59). Furthermore, increased IL-33 can trigger endothelin-1 (ET-1)-induced secretion of prostaglandin E2 (PGE2) and activate TRP channels in psoriatic lesions, resulting in hyperalgesia (60). Recently, biological treatments targeting psoriatic pro-inflammatory factors have been shown to significantly alleviate symptoms of skin discomfort. For example, treatment with secukinumab and ixekizumab, a monoclonal antibody that selectively neutralizes IL-17A, resulted in a reduction of psoriasis-related scalp pain and itching $(61,62)$. Additionally, apremilast, an oral small molecule phosphodiesterase-4 inhibitor that elevates cAMP levels in immune cells, downregulates the production of proinflammatory mediators, such as TNF- $\alpha$, IL-17, and IL-23 and increases the production of anti-inflammatory mediators (63). Apremilast also provides rapid and sustained improvement of pruritus and discomfort and pain of the skin (64). These studies support the speculation that the abnormal nociceptive neuronal function found in psoriasis maybe a result of increased pro-inflammatory factors.

Excessive innervation in psoriatic lesions is considered another important cause of itching and hyperalgesia. It was reported that there is a clinical correlation between skin sensitivity and increased nerve fiber density (65). The number of $\mathrm{PGP}^{+} 5^{+}$nerve fibers in psoriatic lesions is positively correlated with pruritus intensity (VAS score) (66). Furthermore, animal experiments show that decreased nerve innervation is accompanied by pruritus alleviation in mice (43). Elevated NGF levels, also contribute to pruritus and hyperalgesia. It was reported that itching in psoriatic lesions is accompanied by an elevation in NGF levels (67). Moreover, local injection of NGF in human skin can directly lead to a reduction in both thermal/cold pain thresholds and mechanical/electrical pain thresholds (68). Apart from prompting the growth of nerve fibers, NGF also can directly induce increased axonal excitability of sensory nerve fibers leading to hyperalgesia (69).

\section{NOCICEPTIVE NEURONS REGULATE IMMUNE RESPONSE IN PSORIASIS}

TRP channels are often co-expressed with the neuropeptides CGRP, SP, and VIP. The TRPA1/TRPV1-evoked release of neuropeptides can cause neurogenic inflammation (11, 70). Here we will focus on the regulation of neuropeptides on Th17 immune responses, which play an important role in the inflammatory pathology observed in psoriasis $(71,72)$.

\section{Neuropeptides Prompt Th17 Immune Responses}

Functional neuropeptide receptors, such as NK1R (73), RAMP (74), vasoactive intestinal polypeptide receptor 1 (VPAC1), and VPAC2 (75) are expressed on T cells.

In the presence of TGF- $\beta$, SP can prompt Th17 cell differentiation through mediation by $\operatorname{NK} 1 \mathrm{R}(76,77)$. Moreover, SP and HK-1, mediated through NK1R, can prompt Th17 to produce IL-17 (78). NK1R expression on Th17 cells can in turn be upregulated by IL-17A, indicating a positive loop between IL-17A and SP (79). It has recently been confirmed that NK1R signaling is necessary to sustain Th17 cell survival and to maintain efficient immune function (73). CGRP has the same function. By binding to RAMP1 on Th17, CGRP directly upregulates IL-17 production and the expression of IL-23R (80). It has been confirmed in vivo that, IL-17 production is significantly suppressed in T cells from T cell-specific RAMP1-deficient mice (80). 
VIP also plays a role in Th17 differentiation and function through its two receptors, VPAC1 and VPAC2. However, the role of VIP is still under debate. In vitro, VIP-VPAC1 axis signals can bias the CD4 $\mathrm{T}$ cell response toward a Th17rich inflammatory type response, in the presence of TGF- $\beta$ (81). Furthermore, during the onset of Th17 differentiation, VIP prompts the upregulation of the STAT3 gene interaction with the VPAC1 receptor. Moreover, through the VPAC1 and VPAC2 receptors, VIP modulates the upregulation of the transcription factors RAR-related orphan receptor C (RORC), RAR-related orphan receptor A (RORA), and IL-17A genes (75). However, several animal experiments have resulted in conflicting conclusions. In a collagen-induced arthritis (CIA) mouse model (82), a non-obese diabetic (NOD) mouse model (83), and an experimental autoimmune encephalomyelitis (EAE) mouse model (84), VIP suppressed the Th17/Th1-type response. There exists an interesting phenomenon that, based on the same EAE mouse model, two studies selectively knockout (KO) VPAC1 or VPAC2, with conflicting conclusions. In the mice that lacked the VPAC2 receptor, there was an exacerbation of EAE-type clinical, histopathological, and immunological symptoms as well as increased inflammatory Th1/Th17 responses (85). Mice that lacked the VPAC1 gene exhibited a resistance to the development of EAE through the prevention of CNS chemokine upregulation and inflammatory cells infiltration (86). These studies showed that VIP-VPAC1 can enhance Th17 differentiation in vitro, while VIP-VPAC2 signals may suppress Th17 responses. Furthermore, the complicated immune environment may interfere with the role of the VIP-VPAC signal in Th17 responses.

Differentiation of Th17 is controlled by T cell receptor (TCR) activation/co-simulation and a distinct set of cytokines, IL-6 and IL-23, participate in terminal differentiation of Th17 cells to help them attain full functionality (87). Numerous studies show that antigen-presenting cells (APC), including monocytes, dendritic cells (DCs), Langerhans cells (LCs), and endothelial cells, express functional neuropeptide receptors, such as RAMP, NKRs, VPAC1, VPAC2, making it possible for neuropeptides to bias APC-induced immune responses (88-90). Tachykinins (SP and HK-1) can enhance the generation of Th17 cells by elevating expression of IL-1b, IL-6, and IL-23 on monocytes $(79,91)$. It has been confirmed in vivo that, SP-NK1R signals can augment the acquisition of MHC II on bone marrow-derived dendritic cells, which then affect Th17 cell infiltration and activity (92). VIP and pituitary adenylate cyclase activating polypeptides (PACAP) have the same effect. In vitro exposure of LCs to PACAP and VIP have been found to bias LC antigen presentation toward Th17 cell responses. Furthermore, it was found that, after the application of a contact sensitizer, intradermally administered VIP or PACAP are able to enhance the production of IL-17A from drained lymph node $\mathrm{CD} 4^{+} \mathrm{T}$ cells (93). CGRP is also a Th17 response modifier by way of its actions on APC. CGRP stimulates endothelial cells to produce IL-6, which skews the outcome of the presentation of antigens by LC toward a Th17 response (94). These studies show that the neuropeptides, CGRP, SP, VIP, and PACAP, play an important role in regulating Th17 responses through corresponding receptors that are expressed on APC and Th17 cells.
It has recently been highlighted that the interaction between nociceptive neurons and Th17 responses is involved in psoriasislike inflammation and Candida albicans (C. albicans) infections. After detection of C. albicans, TRPV ${ }^{+}$nociceptive neurons drive IL-23 production by releasing CGRP from dermal CD301b ${ }^{+}$DCs. CGRP then evokes dermal $\gamma \delta \mathrm{T}$ cells to produce IL-17, which results in protection from C. albicans (95). In a recent study using a transgenic experimental mouse model, it was found that peripheral TRPV1 ${ }^{+}$neuron activation, by isolated stimulation, is able to trigger psoriasis-like dermatitis and type 17 inflammation by local TCR $\gamma \delta \mathrm{T}$ cells, which can be blocked by botulinum neurotoxin A (BoNT/A) (96). Moreover, onabotulinumtoxinA can significantly decrease PASI and physician global assessment (PGA) scores in patients with psoriasis (97). Both BoNT/A and onabotulinumtoxinA are botulinum toxins (Botox) that can block neuronal vesicle release (98), demonstrating the efficacy of nerve-targeting treatments in psoriasis. This research suggests that TRPV $1^{+}$ nociceptive neurons play a crucial role in the Th17 immune response via the release of neuropeptides from free terminals in psoriasis.

\section{TRPV1+/TRPA1+ Nociceptive Neurons Regulate Immunity in a Psoriatic Mouse Model}

Pharmacological ablation of $\mathrm{TRPV}^{+}$fibers result in significantly alleviated psoriasis-like lesions accompanied by decreased expression of IL-23, IL-17, and IL-22 and decreased recruitment of inflammatory cells in the murine model of psoriasiform skin inflammation (99). It was further confirmed that key inflammatory factors in psoriatic and epidermal hyperplasia are significantly reduced in TRPV1 KO mice (100).

It is mentioned above that there is cross-regulation of function between TRPV1 and TRPA1. In recent years, the role of TRPA1 in psoriasis has been explored. Kemény et al. reported that TRPA1 KO or TRPA1 antagonists (A967079) treatment can both significantly enhance psoriasis dermatitis and increase hind paw scratching, suggesting that TRPA1 plays a protective role in psoriasis (101). However, Zhou et al. hold the opposite opinion that, compared with wildtype (WT) mice, IMQ-induced psoriasiform dermatitis and Th17-related cytokine expression is significantly reduced in TRPA1 KO mice. The authors attribute this contradictory result to the fact that Zhou used a different protocol than Kemény. Zhou used an original experimental protocol that required a relatively higher dose of IMQ, while Kemény used the Finn chamber, which is characterized as a "localized model." It is confirmed that high doses of IMQ induce splenomegaly, increased plasma concentration of inflammatory cytokines, and body weight loss indicating systemic inflammatory reactions in mice, which can be avoid in the Finn chamber application (102). As a result, we can speculate that the immune mediation function of TRPA $1^{+}$ nociceptive neurons may be influenced by the systemic immune environment. 


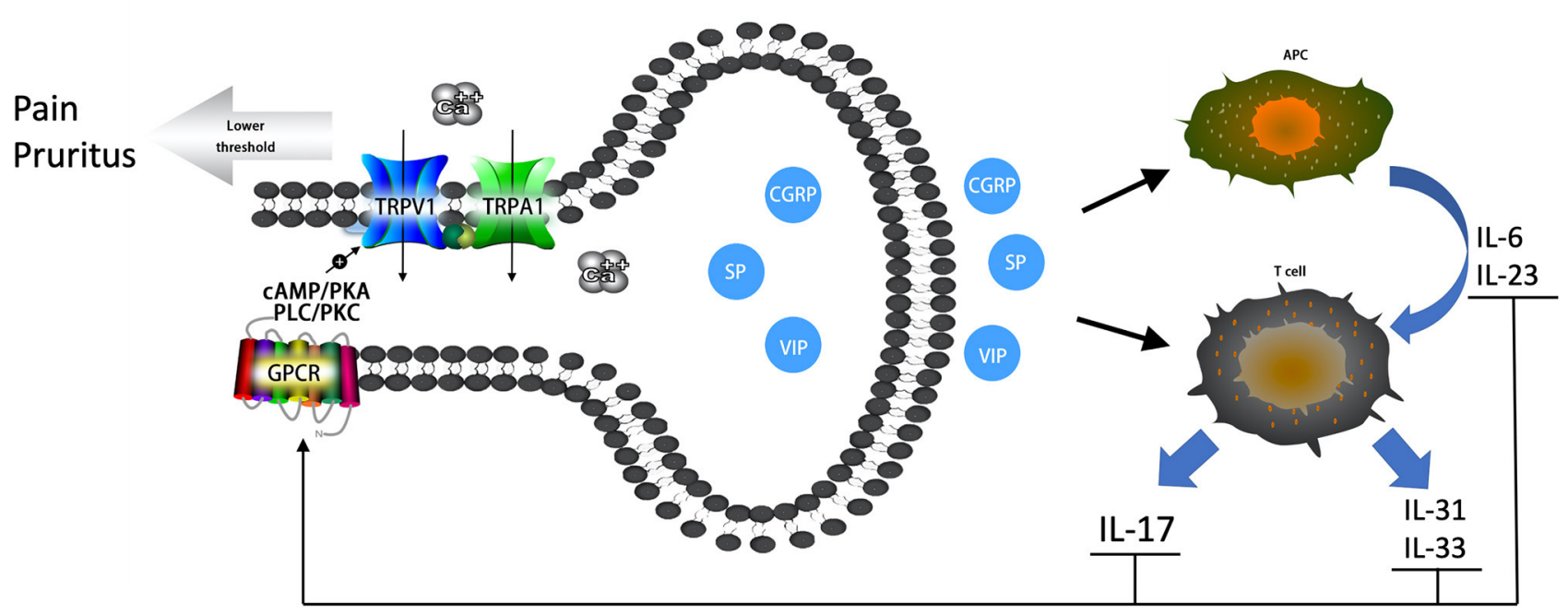

FIGURE 1 | The vicious circular pathway between nociceptive neurons and Th17 immune responses in psoriatic lesions. Neuropeptides (CGRP, SP, VIP) prompt the release of IL-6 and IL-23 and bias antigen presentation for Th17 cell responses. Neuropeptides also prompt Th cells to release IL-17, IL-31, and IL-33. Increased cytokines can sensitize TRPV1 and TRPA1 channels through GPCRs via secondary messenger-signaling pathways, the cAMP/PKA and PLC/PKC pathways, following $\mathrm{Ca}^{2+}$ elevation. An elevated $\mathrm{Ca}^{2+}$ concentrate prompts the release of neuropeptides, which forms a vicious circle pathway between nociceptive neurons and the local immune system. Sensitized TRPV1 and TRPA1 channels result in pruritus, pain, and hyperalgesia experienced by patients with psoriasis.

\section{CONCLUSION}

The primary emphasis of this review has been on examining the role of the nervous system, especially nociceptive neurons, in the pathogenesis of psoriasis (Figure 1). Numerous studies have reported increased innervation of primary sensory nerve fibers and elevated gene expression of TRP channels in psoriasis. However, the dynamic changes of nociceptive neurons in psoriatic lesions are still not fully understood. Moreover, further research is needed to illuminate the role of TRPA $1^{+}$nociceptive neurons in psoriatic immune responses. The vicious circular pathway between nociceptive neurons and Th17 responses is responsible for pruritus, pain, and hyperalgesia experienced by patients with psoriasis. The effective targeting of this pathway is the reason anti-IL-17 therapy proved most effective in reducing pruritus, while traditional immune system suppressants (methotrexate and retinoids) failed (103). This review also provides a theoretical basis for the formulation of promising

\section{REFERENCES}

1. Abraira VE, Ginty DD. The sensory neurons of touch. Neuron. (2013) 79:618-39. doi: 10.1016/j.neuron.2013.07.051

2. Chesler AT. The functional and anatomical dissection of somatosensory subpopulations using mouse genetics. (2014) 8:21. doi: 10.3389/fnana.2014.00021

3. Ellison DL. Physiology of pain. Crit Care Nurs Clin North Am. (2017) 29:397-406. doi: 10.1016/j.cnc.2017.08.001

4. Basbaum AI, Bautista DM, Scherrer G, Julius D. Cellular and molecular mechanisms of pain. Cell. (2009) 139:267-84. doi: 10.1016/j.cell.200 9.09 .028 nerve-targeting treatments for psoriasis in the future. However, further clinical trials are still needed to understand the effectiveness of Botox. It will be beneficial for future studies to continue to explore the synergy between nociceptive neurons and the immune system in psoriasis, which could result in improved patient outcomes.

\section{AUTHOR CONTRIBUTIONS}

$\mathrm{XZ}$ wrote the manuscript. $\mathrm{YH}$ approved the final version of the manuscript. All authors contributed to the article and approved the submitted version.

\section{FUNDING}

This work was supported by grants from the National Natural Science Foundation of China (NSFC), grant number: 81773314.
5. Hawkes JE, Chan TC, Krueger JG. Psoriasis pathogenesis and the development of novel targeted immune therapies. $J$ Allergy Clin Immunol. (2017) 140:645-53. doi: 10.1016/j.jaci.201 7.07.004

6. Zhu TH, Nakamura M, Farahnik B, Abrouk M, Lee K, Singh R, et al. The role of the nervous system in the pathophysiology of psoriasis: a review of cases of psoriasis remission or improvement following denervation injury. Am J Clin Dermatol. (2016) 17:257-63. doi: 10.1007/s40257-0160183-7

7. Stewart TJ, Tong W, Whitfeld MJ. The associations between psychological stress and psoriasis: a systematic review. Int J Dermatol. (2018) 57:127582. doi: $10.1111 /$ ijd.13956 
8. Hunter HJ, Griffiths CE, Kleyn CE. Does psychosocial stress play a role in the exacerbation of psoriasis? Br J Dermatol. (2013) 169:96574. doi: $10.1111 /$ bjd. 12478

9. Lim DS, Bewley A, Oon HH. Psychological profile of patients with psoriasis. Ann Acad Med Singapore. (2018) 47:516-22.

10. Ramsey IS, Delling $M$, Clapham DE. An introduction to TRP channels. Annu Rev Physiol. (2006) 68:61947. doi: 10.1146/annurev.physiol.68.040204.100431

11. Boillat A, Alijevic O, Kellenberger S. Calcium entry via TRPV1 but not ASICs induces neuropeptide release from sensory neurons. Mol Cell Neurosci. (2014) 61:13-22. doi: 10.1016/j.mcn.2014.04.007

12. Kobayashi K, Fukuoka T, Obata K, Yamanaka H, Dai Y, Tokunaga A, et al. Distinct expression of TRPM8, TRPA1, and TRPV1 mRNAs in rat primary afferent neurons with adelta/c-fibers and colocalization with trk receptors. $J$ Comp Neurol. (2005) 493:596-606. doi: 10.1002/cne.20794

13. Ruparel NB, Patwardhan AM, Akopian AN, Hargreaves KM. Homologous and heterologous desensitization of capsaicin and mustard oil responses utilize different cellular pathways in nociceptors. Pain. (2008) 135:2719. doi: 10.1016/j.pain.2007.06.005

14. Akopian AN. Regulation of nociceptive transmission at the periphery via TRPA1-TRPV1 interactions. Curr Pharm Biotechnol. (2011) 12:8994. doi: 10.2174/138920111793937952

15. Spahn V, Stein C, Zollner C. Modulation of transient receptor vanilloid 1 activity by transient receptor potential ankyrin 1. Mol Pharmacol. (2014) 85:335-44. doi: 10.1124/mol.113.088997

16. Weng HJ, Patel KN, Jeske NA, Bierbower SM, Zou W, Tiwari V, et al. Tmem100 Is a regulator of TRPA1-TRPV1 complex and contributes to persistent pain. Neuron. (2015) 85:833-46. doi: 10.1016/j.neuron.2014.12.065

17. Ma W, Quirion R. Inflammatory mediators modulating the transient receptor potential vanilloid 1 receptor: therapeutic targets to treat inflammatory and neuropathic pain. Expert Opin Ther Targets. (2007) 11:307-20. doi: 10.1517/14728222.11.3.307

18. Koop LK, Hawkins JL, Cornelison LE, Durham PL. Central role of protein kinase $\mathrm{A}$ in promoting trigeminal nociception in an in vivo model of temporomandibular disorders. J Oral Facial Pain Headache. (2017) 31:26474. doi: $10.11607 /$ ofph.1803

19. Liang R, Liu X, Wei L, Wang W, Zheng P, Yan X, et al. The modulation of the excitability of primary sensory neurons by $\mathrm{Ca}(2)(+)$-CaM-CaMKII pathway. Neurol Sci. (2012) 33:1083-93. doi: 10.1007/s10072-011-0907-7

20. Roosterman D, Goerge T, Schneider SW, Bunnett NW, Steinhoff M. Neuronal control of skin function: the skin as a neuroimmunoendocrine organ. Physiol Rev. (2006) 86:1309-79. doi: 10.1152/physrev.00026.2005

21. Cunha FQ, Poole S, Lorenzetti BB, Ferreira SH. The pivotal role of tumour necrosis factor alpha in the development of inflammatory hyperalgesia. $\mathrm{Br} J$ Pharmacol. (1992) 107:660-4. doi: 10.1111/j.1476-5381.1992.tb14503.x

22. Konig C, Zharsky M, Moller C, Schaible HG, Ebersberger A. Involvement of peripheral and spinal tumor necrosis factor alpha in spinal cord hyperexcitability during knee joint inflammation in rats. Arthritis Rheumatol. (2014) 66:599-609. doi: 10.1002/art.38271

23. Ji RR, Xu ZZ, Gao YJ. Emerging targets in neuroinflammation-driven chronic pain. Nat Rev Drug Discov. (2014) 13:533-48. doi: 10.1038/nrd4334

24. Amaya F, Izumi Y, Matsuda M, Sasaki M. Tissue injury and related mediators of pain exacerbation. Curr Neuropharmacol. (2013) 11:5927. doi: 10.2174/1570159X11311060003

25. Richter F, Natura G, Ebbinghaus M, von Banchet GS, Hensellek S, König $\mathrm{C}$, et al. Interleukin-17 sensitizes joint nociceptors to mechanical stimuli and contributes to arthritic pain through neuronal interleukin-17 receptors in rodents. Arthritis Care Res. (2012) 64:4125-34. doi: 10.1002/ar t.37695

26. Chatchaisak D, Srikiatkhachorn A, Maneesri-le Grand S, Govitrapong P, Chetsawang B. The role of calcitonin gene-related peptide on the increase in transient receptor potential vanilloid-1 levels in trigeminal ganglion and trigeminal nucleus caudalis activation of rat. J Chem Neuroanat. (2013) 47:50-6. doi: 10.1016/j.jchemneu.2012.09.005

27. Chatchaisak D, Connor M, Srikiatkhachorn A, Chetsawang B. The potentiating effect of calcitonin gene-related peptide on transient receptor potential vanilloid-1 activity and the electrophysiological responses of rat trigeminal neurons to nociceptive stimuli. J Physiol Sci. (2017) 68:2618. doi: 10.1007/s12576-017-0529-9

28. Nattkemper LA, Tey HL, Valdes-Rodriguez R, Lee H, Mollanazar NK, Albornoz $\mathrm{C}$, et al. The genetics of chronic itch: gene expression in the skin of patients with atopic dermatitis and psoriasis with severe itch. J Invest Dermatol. (2018) 138:1311-7. doi: 10.1016/j.jid.2017.12.029

29. Zhou Y, Han D, Follansbee T, Wu X, Yu S, Wang B, et al. Transient receptor potential ankyrin 1 (TRPA1) positively regulates imiquimodinduced, psoriasiform dermal inflammation in mice. J Cell Mol Med. (2019) 23:4819-28. doi: 10.1111/jcmm.14392

30. Feng J, Yang P, Mack MR, Dryn D, Luo J, Gong X, et al. Sensory TRP channels contribute differentially to skin inflammation and persistent itch. Nat Commun. (2017) 8:980. doi: 10.1038/s41467-017-01056-8

31. Taneda K, Tominaga M, Negi O, Tengara S, Kamo A, Ogawa $\mathrm{H}$, et al. Evaluation of epidermal nerve density and opioid receptor levels in psoriatic itch. Br J Dermatol. (2011) 165:27784. doi: 10.1111/j.1365-2133.2011.10347.x

32. Kim T-W, Shim W-H, Kim J-M, Mun J-H, Song M, Kim H-S, et al. Clinical characteristics of pruritus in patients with scalp psoriasis and their relation with intraepidermal nerve fiber density. Ann Dermatol. (2014) 26:727-32. doi: 10.5021/ad.2014.26.6.727

33. Kou K, Nakamura F, Aihara M, Chen H, Seto K, Komori-Yamaguchi J, et al. Decreased expression of semaphorin-3A, a neurite-collapsing factor, is associated with itch in psoriatic skin. Acta Derm Venerol. (2012) 92:5218. doi: 10.2340/00015555-1350

34. Cui S, Xiao T, Wang Y, Lu H, Wang Y, Gao X-H, et al. Morphological relationship between nerve fibers and Langerhans cells in the epidermis of psoriasis vulgaris and lichen simplex chronicus. J Dermatol Sci. (2009) 56:132-4. doi: 10.1016/j.jdermsci.2009.07.009

35. Kubanov AA, Katunina OR, Chikin VV. Expression of neuropeptides, neurotrophins, and neurotransmitters in the skin of patients with atopic dermatitis and psoriasis. Bull Exp Biol Med. (2015) 159:31822. doi: 10.1007/s10517-015-2951-4

36. Pergolizzi S, Vaccaro M, Magaudda L, Mondello MR, Arco A, Bramanti P, et al. Immunohistochemical study of epidermal nerve fibres in involved and uninvolved psoriatic skin using confocal laser scanning microscopy. Arch Dermatol Res. (1998) 290:483-9. doi: 10.1007/s004030050340

37. El-Nour H, Santos A, Nordin M, Jonsson P, Svensson M, Nordlind K, et al. Neuronal changes in psoriasis exacerbation. J Eur Acad Dermatol Venereol. (2009) 23:1240-5. doi: 10.1111/j.1468-3083.2009.03287.x

38. Levi-Montalcini R. The nerve growth factor: its widening role and place in neurobiology. Adv Biochem Psychopharmacol. (1976) 15:237-50.

39. Nilsson A, Kanje M. Amphiregulin acts as an autocrine survival factor for adult sensory neurons. Neuroreport. (2005) 16:213-8. doi: 10.1097/00001756-200502280-00002

40. Tanelian DL, Barry MA, Johnston SA, Le T, Smith GM. Semaphorin III can repulse and inhibit adult sensory afferents in vivo. Nat Med. (1997) 3:1398-401. doi: 10.1038/nm1297-1398

41. Smolyannikova VA, Kubanova AA, Karamova AE, Nefedova MA, Chikin VV. [Role of the skin expression of neuropeptides, neurotrophins and their receptors in the pathogenesis of dermatoses]. Arkh Patol. (2015) 77:339. doi: 10.17116/patol201577433-39

42. Raychaudhuri SP, Raychaudhuri SK. Role of NGF and neurogenic inflammation in the pathogenesis of psoriasis. Prog Brain Res. (2004) 146:433-7. doi: 10.1016/S0079-6123(03)46027-5

43. Sakai K, Sanders KM, Youssef MR, Yanushefski KM, Jensen LE, Yosipovitch $\mathrm{G}$, et al. Role of neurturin in spontaneous itch and increased nonpeptidergic intraepidermal fiber density in a mouse model of psoriasis. Pain. (2017) 158:2196-202. doi: 10.1097/j.pain.0000000000001025

44. Lawson SN. Peptides and cutaneous polymodal nociceptor neurones. Prog Brain Res. (1996) 113:369-85. doi: 10.1016/S0079-6123(08)61099-7

45. Fink T, Weihe E. Multiple neuropeptides in nerves supplying mammalian lymph nodes: messenger candidates for sensory and autonomic neuroimmunomodulation? Neurosci Lett. (1988) 90:39-44. doi: 10.1016/0304-3940(88)90783-5

46. Sandoval-Talamantes AK, Gomez-Gonzalez BA, Uriarte-Mayorga DF, Martinez-Guzman MA, Wheber-Hidalgo KA, Alvarado-Navarro A. Neurotransmitters, neuropeptides and their receptors interact with 
immune response in healthy and psoriatic skin. Neuropeptides. (2020) 79:102004. doi: 10.1016/j.npep.2019.102004

47. Jiang WY, Raychaudhuri SP, Farber EM. Double-labeled immunofluorescence study of cutaneous nerves in psoriasis. Int J Dermatol. (1998) 37:572-4. doi: 10.1046/j.1365-4362.1998.00533.x

48. Joachim RA, Kuhlmei A, Dinh QT, Handjiski B, Fischer T, Peters EMJ, et al. Neuronal plasticity of the "brain-skin connection": stress-triggered up-regulation of neuropeptides in dorsal root ganglia and skin via nerve growth factor-dependent pathways. J Mol Med. (2007) 85:136978. doi: $10.1007 / \mathrm{s} 00109-007-0236-8$

49. Al'Abadie MS, Senior HJ, Bleehen SS, Gawkrodger DJ. Neuropeptides and general neuronal marker in psoriasis-an immunohistochemical study. Clin Exp Dermatol. (1995) 20:384-9. doi: 10.1111/j.1365-2230.1995.tb01354.x

50. Guo R, Li F-F, Chen M-L, Ya M-Z, He H-L, Li D. The role of CGRP and CALCA T-692C single-nucleotide polymorphism in psoriasis vulgaris. Pharmazie. (2015) 70:88-93.

51. Reich A, Orda A, Wiśnicka B, Szepietowski JC. Plasma concentration of selected neuropeptides in patients suffering from psoriasis. Exp Dermatol. (2007) 16:421-8. doi: 10.1111/j.1600-0625.2007.00544.x

52. Ljosaa TM, Rustoen T, Mørk C, Stubhaug A, Miaskowski C, Paul SM, et al. Skin pain and discomfort in psoriasis: an exploratory study of symptom prevalence and characteristics. Acta Derm Venerol. (2010) 90:3945. doi: 10.2340/00015555-0764

53. Patruno C, Napolitano M, Balato N, Ayala F, Megna M, Patrì A, et al. Psoriasis and skin pain: instrumental and biological evaluations. Acta Derm Venerol. (2015) 95:432-8. doi: 10.2340/00015555-1965

54. Baumbach P, Weiss T, Giermann C, Cubillos S, Meissner W, Norgauer J. Standardized quantitative sensory testing in patients with psoriasis vulgaris: evidence for altered large and small fibre functioning. J Eur Acad Dermatol Venereol. (2016) 30:e137-40. doi: 10.1111/jdv.13448

55. Yosipovitch G, Chan YH, Tay YK, Goh CL. Thermosensory abnormalities and blood flow dysfunction in psoriatic skin. Br J Dermatol. (2003) 149:4927. doi: 10.1046/j.1365-2133.2003.05585.x

56. Dowlatshahi EA, van der Voort EA, Arends LR, Nijsten T. Markers of systemic inflammation in psoriasis: a systematic review and meta-analysis. Br J Dermatol. (2013) 169:266-82. doi: 10.1111/bjd.12355

57. Ljosaa TM, Stubhaug A, Mork C, Moum T, Wahl AK. Improvement in psoriasis area and severity index score predicts improvement in skin pain over time in patients with psoriasis. Acta Derm Venereol. (2013) 93:3304. doi: $10.2340 / 00015555-1456$

58. Cannav x00F2 SP, Bertino L, Di Salvo E, Papaianni V, VenturaSpagnolo E, Gangemi S. Possible roles of IL-33 in the innate-adaptive immune crosstalk of psoriasis pathogenesis. Mediat Inflamm. (2019) 2019:7158014. doi: 10.1155/2019/7158014

59. Verri WA Jr., Guerrero AT, Fukada SY, Valerio DA, Cunha TM, $\mathrm{Xu} \mathrm{D}$, et al. IL-33 mediates antigen-induced cutaneous and articular hypernociception in mice. Proc Natl Acad Sci USA. (2008) 105:27238. doi: 10.1073/pnas.0712116105

60. Ma W, St-Jacques B, Rudakou U, Kim YN. Stimulating TRPV1 externalization and synthesis in dorsal root ganglion neurons contributes to PGE2 potentiation of TRPV1 activity and nociceptor sensitization. Eur J Pain. (2017) 21:575-93. doi: 10.1002/ejp.959

61. Reich K, Pinter A, Lacour JP, Ferrandiz C, Micali G, French LE, et al. Comparison of ixekizumab with ustekinumab in moderate-to-severe psoriasis: 24-week results from IXORA-S, a phase III study. $\mathrm{Br}$ J Dermatol. (2017) 177:1014-23. doi: 10.1111/bjd.15666

62. Feldman SR, Green L, Kimball AB, Siu K, Zhao Y, Herrera V, et al. Secukinumab improves scalp pain, itching, scaling and quality of life in patients with moderate-to-severe scalp psoriasis. J Dermatol Treat. (2017) 28:716-21. doi: 10.1080/09546634.2017.1329502

63. Schafer PH, Parton A, Capone L, Cedzik D, Brady H, Evans JF, et al. Apremilast is a selective PDE4 inhibitor with regulatory effects on innate immunity. Cell Signal. (2014) 26:2016-29. doi: 10.1016/j.cellsig.2014.05.014

64. Sobell JM, Foley P, Toth D, Mrowietz U, Girolomoni G, Goncalves $\mathrm{J}$, et al. Effects of apremilast on pruritus and skin discomfort/pain correlate with improvements in quality of life in patients with moderate to severe plaque psoriasis. Acta Derm Venereol. (2016) 96:514-20. doi: 10.2340/00015555-2360
65. Buddenkotte J, Steinhoff M. Pathophysiology and therapy of pruritus in allergic and atopic diseases. Allergy. (2010) 65:805-21. doi: 10.1111/j.1398-9995.2010.01995.x

66. Kupczyk P, Reich A, Gajda M, Hołysz M, Wysokińska E, Paprocka M, et al. UCHL1/PGP 9.5 dynamic in neuro-immune-cutaneous milieu: focusing on axonal nerve terminals and epidermal keratinocytes in psoriatic itch. Biomed Res Int. (2018) 2018:7489316. doi: 10.1155/2018/7489316

67. Nakamura M, Toyoda M, Morohashi M. Pruritogenic mediators in psoriasis vulgaris: comparative evaluation of itch-associated cutaneous factors. $\mathrm{Br} \mathrm{J}$ Dermatol. (2003) 149:718-30. doi: 10.1046/j.1365-2133.2003.05586.x

68. Rukwied R, Mayer A, Kluschina O, Obreja O, Schley M, Schmelz M. NGF induces non-inflammatory localized and lasting mechanical and thermal hypersensitivity in human skin. Pain. (2010) 148:40713. doi: $10.1016 /$ j.pain.2009.11.022

69. Hirth M, Rukwied R, Gromann A, Turnquist B, Weinkauf B, Francke K, et al. Nerve growth factor induces sensitization of nociceptors without evidence for increased intraepidermal nerve fiber density. Pain. (2013) 154:250011. doi: 10.1016/j.pain.2013.07.036

70. Wang XL, Cui LW, Liu Z, Gao YM, Wang S, Li H, et al. Effects of TRPA1 activation and inhibition on TRPA1 and CGRP expression in dorsal root ganglion neurons. Neural Regen Res. (2019) 14:1408. doi: $10.4103 / 1673-5374.243719$

71. Ogawa E, Sato Y, Minagawa A, Okuyama R. Pathogenesis of psoriasis and development of treatment. J Dermatol. (2018) 45:264-72. doi: 10.1111/1346-8138.14139

72. Brembilla NC, Senra L, Boehncke WH. The IL-17 family of cytokines in psoriasis: IL-17A and beyond. Front Immunol. (2018) 9:1682. doi: 10.3389/fimmu.2018.01682

73. Morelli AE, Sumpter TL, Rojas-Canales DM, Bandyopadhyay M, Chen Z, Tkacheva $O$, et al. Neurokinin-1 receptor signaling is required for efficient $\mathrm{Ca}^{2+}$ flux in T-cell-receptor-activated T cells. Cell Rep. (2020) 30:3448-65 e8. doi: 10.1016/j.celrep.2020.02.054

74. Liu J, Chen $\mathrm{M}$, Wang $\mathrm{X}$. Calcitonin gene-related peptide inhibits lipopolysaccharide-induced interleukin-12 release from mouse peritoneal macrophages, mediated by the cAMP pathway. Immunology. (2000) 101:617. doi: 10.1046/j.1365-2567.2000.00082.x

75. Jimeno R, Leceta J, Martinez C, Gutierrez-Canas I, Carrion M, PerezGarcia S, et al. Vasoactive intestinal peptide maintains the nonpathogenic profile of human th17-polarized cells. J Mol Neurosci. (2014) 54:51225. doi: 10.1007/s12031-014-0318-3

76. Beinborn M, Blum A, Hang L, Setiawan T, Schroeder JC, Stoyanoff $\mathrm{K}$, et al. TGF-beta regulates T-cell neurokinin-1 receptor internalization and function. Proc Natl Acad Sci USA. (2010) 107:4293-8. doi: 10.1073/pnas.0905877107

77. Barros PO, Ferreira TB, Vieira MM, Almeida CR, Araujo-Lima CF, SilvaFilho RG, et al. Substance P enhances Th17 phenotype in individuals with generalized anxiety disorder: an event resistant to glucocorticoid inhibition. J Clin Immunol. (2011) 31:51-9. doi: 10.1007/s10875-010-9466-6

78. Bera MM, Lu B, Martin TR, Cui S, Rhein LM, Gerard C, et al. Th17 cytokines are critical for respiratory syncytial virus-associated airway hyperreponsiveness through regulation by complement $\mathrm{C} 3 \mathrm{a}$ and tachykinins. J Immunol. (2011) 187:4245-55. doi: 10.4049/jimmunol.1101789

79. Vilisaar J, Kawabe K, Braitch M, Aram J, Furtun Y, Fahey AJ, et al. Reciprocal regulation of substance P and IL-12/IL-23 and the associated cytokines, IFNgamma/IL-17: a perspective on the relevance of this interaction to multiple sclerosis. J Neuroimmune Pharmacol. (2015) 10:45767. doi: 10.1007/s11481-015-9589-x

80. Mikami N, Watanabe K, Hashimoto N, Miyagi Y, Sueda K, Fukada S-i, et al. Calcitonin gene-related peptide enhances experimental autoimmune encephalomyelitis by promoting Th17-cell functions. Int Immunol. (2012) 24:681-91. doi: 10.1093/intimm/dxs075

81. Yadav M, Rosenbaum J, Goetzl EJ. Cutting edge: vasoactive intestinal peptide (VIP) induces differentiation of Th17 cells with a distinctive cytokine profile. J Immunol. (2008) 180:2772-6. doi: 10.4049/jimmunol.180.5.2772

82. Deng S, Xi Y, Wang H, Hao J, Niu X, Li W, et al. Regulatory effect of vasoactive intestinal peptide on the balance of Treg and Th17 in collagen-induced arthritis. Cell Immunol. (2010) 265:10510. doi: $10.1016 /$ j.cellimm.2010.07.010 
83. Jimeno R, Gomariz RP, Gutierrez-Canas I, Martinez C, Juarranz Y, Leceta J. New insights into the role of VIP on the ratio of T-cell subsets during the development of autoimmune diabetes. Immunol Cell Biol. (2010) 88:73445. doi: 10.1038/icb.2010.29

84. Abad C, Tan YV, Lopez R, Nobuta H, Dong H, Phan P, et al. Vasoactive intestinal peptide loss leads to impaired CNS parenchymal T-cell infiltration and resistance to experimental autoimmune encephalomyelitis. Proc Natl Acad Sci USA. (2010) 107:19555-60. doi: 10.1073/pnas.1007622107

85. Tan YV, Abad C, Wang Y, Lopez R, Waschek J. VPAC2 (vasoactive intestinal peptide receptor type 2) receptor deficient mice develop exacerbated experimental autoimmune encephalomyelitis with increased Th1/Th17 and reduced Th2/Treg responses. Brain Behav Immun. (2015) 44:16775. doi: 10.1016/j.bbi.2014.09.020

86. Abad C, Jayaram B, Becquet L, Wang Y, O'Dorisio MS, Waschek JA, et al. VPAC1 receptor (Vipr1)-deficient mice exhibit ameliorated experimental autoimmune encephalomyelitis, with specific deficits in the effector stage. $J$ Neuroinflamm. (2016) 13:169. doi: 10.1186/s12974-016-0626-3

87. Song $\mathrm{X}$, Gao $\mathrm{H}$, Qian $\mathrm{Y}$. Th17 differentiation and their proinflammation function. Adv Exp Med Biol. (2014) 841:99151. doi: 10.1007/978-94-017-9487-9_5

88. Ganea D, Hooper KM, Kong W. The neuropeptide vasoactive intestinal peptide: direct effects on immune cells and involvement in inflammatory and autoimmune diseases. Acta Physiol. (2015) 213:442-52. doi: 10.1111/apha.12427

89. Suvas S. Role of substance $P$ neuropeptide in inflammation, wound healing, and tissue homeostasis. J Immunol. (2017) 199:1543-52. doi: 10.4049/jimmunol.1601751

90. Assas BM, Pennock JI, Miyan JA. Calcitonin gene-related peptide is a key neurotransmitter in the neuro-immune axis. Front Neurosci. (2014) 8:23. doi: $10.3389 /$ fnins. 2014.00023

91. Cunin P, Caillon A, Corvaisier M, Garo E, Scotet M, Blanchard S, et al. The tachykinins substance $\mathrm{P}$ and hemokinin-1 favor the generation of human memory Th17 cells by inducing IL-1 $\beta$, IL-23, and TNF-like 1A expression by monocytes. J Immunol. (2011) 186:4175-82. doi: 10.4049/jimmunol.1002535

92. Yu M, Lee SM, Lee H, Amouzegar A, Nakao T, Chen Y, et al. Neurokinin1 receptor antagonism ameliorates dry eye disease by inhibiting antigenpresenting cell maturation and T helper 17 cell activation. Am J Pathol. (2020) 190:125-33. doi: 10.1016/j.ajpath.2019.09.020

93. Ding W, Manni M, Stohl LL, Zhou XK, Wagner JA, Granstein RD. Pituitary adenylate cyclase-activating peptide and vasoactive intestinal polypeptide bias Langerhans cell Ag presentation toward Th17 cells. Eur J Immunol. (2012) 42:901-11. doi: 10.1002/eji.201141958

94. Ding W, Stohl LL, Xu L, Zhou XK, Manni M, Wagner JA, et al. Calcitonin gene-related peptide-exposed endothelial cells bias antigen presentation to
CD4+ T cells toward a Th17 Response. J Immunol. (2016) 196:218194. doi: 10.4049/jimmunol.1500303

95. Kashem SW, Riedl MS, Yao C, Honda CN, Vulchanova L, Kaplan DH. Nociceptive sensory fibers drive interleukin-23 production from CD301b+ dermal dendritic cells and drive protective cutaneous immunity. Immunity. (2015) 43:515-26. doi: 10.1016/j.immuni.2015.08.016

96. Cohen JA, Edwards TN, Liu AW, Hirai T, Jones MR, Wu J, et al. Cutaneous TRPV1+ neurons trigger protective innate type 17 anticipatory immunity. Cell. (2019) 178:919-32.e14. doi: 10.1016/j.cell.2019.06.022

97. Aschenbeck KA, Hordinsky MK, Kennedy WR, Wendelschafer-Crabb G, Ericson ME, Kavand S, et al. Neuromodulatory treatment of recalcitrant plaque psoriasis with onabotulinumtoxinA. J Am Acad Dermatol. (2018) 79:1156-9. doi: 10.1016/j.jaad.2018.07.058

98. Binz T, Blasi J, Yamasaki S, Baumeister A, Link E, Sudhof TC, et al. Proteolysis of SNAP-25 by types E and A botulinal neurotoxins. J Biol Chem. (1994) 269:1617-20.

99. Riol-Blanco L, Ordovas-Montanes J, Perro M, Naval E, Thiriot A, Alvarez D, et al. Nociceptive sensory neurons drive interleukin23- mediated psoriasiform skin inflammation. Nature. (2014) 510:157-61. doi: 10.1038/nature13199

100. Zhou Y, Follansbee T, Wu X, Han D, Yu S, Domocos DT, et al. TRPV1 mediates inflammation and hyperplasia in imiquimod (IMQ)-induced psoriasiform dermatitis (PsD) in mice. J Dermatol Sci. (2018) 92:26471. doi: 10.1016/j.jdermsci.2018.11.009

101. Kemény Á, Kodji X, Horváth S, Komlódi R, Szoke É, Sándor Z, et al. TRPA1 acts in a protective manner in imiquimod-induced psoriasiform dermatitis in mice. J Investig Dermatol. (2018) 138:1774-84. doi: 10.1016/j.jid.2018.02.040

102. Horvath S, Komlodi R, Perkecz A, Pinter E, Gyulai R, Kemeny A. Methodological refinement of Aldara-induced psoriasiform dermatitis model in mice. Sci Rep. (2019) 9:3685. doi: 10.1038/s41598-019-39903-x

103. Théréné C, Brenaut E, Barnetche T, Misery L. Efficacy of systemic treatments of psoriasis on pruritus: a systemic literature review and meta-analysis. $J$ Invest Dermatol. (2018) 138:38-45. doi: 10.1016/j.jid.2017.05.039

Conflict of Interest: The authors declare that the research was conducted in the absence of any commercial or financial relationships that could be construed as a potential conflict of interest.

Copyright $(\odot) 2020$ Zhang and He. This is an open-access article distributed under the terms of the Creative Commons Attribution License (CC BY). The use, distribution or reproduction in other forums is permitted, provided the original author(s) and the copyright owner(s) are credited and that the original publication in this journal is cited, in accordance with accepted academic practice. No use, distribution or reproduction is permitted which does not comply with these terms. 